\title{
Caen - 21 rue de la Miséricorde
}

$\mathrm{n}^{\circ} 3482$

\section{Hélène Dupont}

\section{(2) OpenEdition \\ Journals}

Édition électronique

URL : http://journals.openedition.org/adlfi/16879

ISSN : 2114-0502

Éditeur

Ministère de la culture

Référence électronique

Hélène Dupont, «Caen - 21 rue de la Miséricorde », ADLFI. Archéologie de la France - Informations [En ligne], Basse-Normandie, mis en ligne le 16 mars 2016, consulté le 19 avril 2019. URL : http:// journals.openedition.org/adlfi/16879

Ce document a été généré automatiquement le 19 avril 2019

(C) Ministère de la Culture et de la Communication, CNRS 


\section{Caen - 21 rue de la Miséricorde}

$n^{\circ} 3482$

\section{Hélène Dupont}

Lien Atlas (MCC) :

http://atlas.patrimoines.culture.fr/atlas/trunk/index.php?

ap_theme=DOM_2.01.02\&ap_bbox=-0.413;49.153;-0.331;49.216

1 L'opération est située à Caen, au 21 rue de la Miséricorde, sur le territoire de l'îlot Saint Jean, aujourd'hui bordé à l'est par le quai Vendeuvre et le bassin Saint-Pierre, et au sud par l'Orne. Le diagnostic, qui s'étend sur $1604 \mathrm{~m}^{2}$, s'est déroulé dans un bâtiment encore en élévation, préalablement au projet de construction d'une résidence pour personnes âgées par l'entreprise STEVA.

Les trois sondages, concentrés sur un tiers de l'emprise de l'aménagement, permettent d'entrevoir une occupation dont la datation est assez large avec une fourchette chronologique comprise entre le bas Moyen Âge et l'époque contemporaine ( $\left.\mathrm{XIV}^{\mathrm{e}}-\mathrm{XIX}{ }^{\mathrm{e}} \mathrm{s}\right)$. En sondage 1, des niveaux de circulation extérieurs correspondant sans doute à une venelle d'accès de la rue des Carmes vers l'intérieur de la parcelle, ont pu fournir les indices d'une occupation médiévale du secteur. Le sondage 2 témoigne d'aménagements hydrauliques modernes liés aux bâtiments alentour. Précisons qu'il n'a pas été possible d'atteindre les niveaux inférieurs et que le potentiel archéologique des sondages pose donc encore question. Le sondage 3 a quant à lui permis de découvrir un bâtiment maçonné visible sur le cadastre napoléonien de 1810 et rasé après les bombardements de 1944. Le mur de façade en pierres calcaires, reconnu sur $1,10 \mathrm{~m}$ de profondeur, est large d'1,30 m et se voit renforcé de contreforts. L'un d'eux, auquel s'ajoute probablement un second, a pu être dégagé. Un niveau de sol construit à l'aide de dalles calcaires de belle facture et des remblais sous-jacents, dont le fond n'a pu être atteint, font soupçonner que le diagnostic n'a pu aborder que les dernières phases d'occupation du site, qui semblent avoir fonctionné entre le $\mathrm{XVII}^{\mathrm{e}}$ et le $\mathrm{XIX}^{\mathrm{e}} \mathrm{s}$. Le peu de céramique recueilli incite cependant à la prudence. La période de construction du bâtiment est à ce jour inconnue puisque la base du mur n'a pas été atteinte et sa tranchée de construction non testée. Seuls des mobiliers recueillis dans les niveaux de construction pourraient nous renseigner sur la 
datation d'un bâtiment dont le mode de construction et l'aspect général peuvent très bien évoquer une construction tant médiévale que moderne. Un tiers du bâtiment est situé dans l'emprise du projet, bâtiment dont la surface au sol totale peut être évaluée à environ $1185 \mathrm{~m}^{2}$. La façade trouvée pourrait même correspondre à celle d'un premier bâtiment allongé d'environ $485 \mathrm{~m}^{2}(44 \times 11 \mathrm{~m})$, première phase de construction d'un vaste ensemble, les trois espaces situés contre sa façade nord-ouest semblant être rajoutés $\left(700 \mathrm{~m}^{2}\right)$.

3 L'approche documentaire permet d'entrevoir le potentiel historique de ce bâtiment, qualifié sur la matrice cadastrale de 1810 de «magasin ». Il s'agirait donc, au moins dans son état 1810, d'un entrepôt de marchandises possédé et occupé par Nicolas HervieuDuclos, l'un des deux plus riches armateurs de la ville de Caen sous le Premier Empire. Une rapide prospection dans la matrice cadastrale nous apprend qu'il possède une bonne partie des locaux de stockage de la parcelle, qu'il occupe une partie des bâtiments de la douane et également l'ancienne église des Carmes. Il est également corsaire pour le compte de Napoléon, avec le lougre corsaire «La Ville de Caen » armé à Saint-Vaast-laHougue. La consultation de plans anciens de Caen fait remonter au moins à 1700 la présence de "la Romaine » sous l'Ancien Régime puis de la douane ensuite, à l'est de notre entrepôt. La situation enclavée et protégée de l'édifice évoque même la possibilité d'une ancienne possession de l'administration. La présence du Grenier à sel, sur la rue des Carmes, juste en face de notre parcelle, ainsi que la localisation de l'entrepôt face au port de Caen sur l'Odon le long de la rue des Quay et du futur bassin Saint-Pierre, élargit le propos vers une problématique rarement abordée par l'archéologie, celle de l'occupation «technique et administrative» d'un port de commerce. Cette problématique peut permettre d'aborder la question de l'activité du port de Caen au Moyen Âge et sous l'Ancien Régime, avec et sans les fortifications de l'îlot Saint-Jean, et donc d'une possible évolution de l'emplacement du cœur du port entre le Moyen Âge et le XIX ${ }^{e}$ s. Il serait également intéressant d'aborder la relation entre les bâtiments administratifs (Romaine / douane et Grenier à sel), les aires de déchargement et de stockage liées à l'activité du commerce local et de longue distance et l'habitat alentour. L'occupation du secteur par les établissements religieux sur l'îlot Saint-Jean près du port de commerce est également à aborder: nous avons vu par exemple que le couvent de la Charité occupe " économiquement » cette partie de l'îlot Saint-Jean par la possession de magasins et d'une manufacture. 


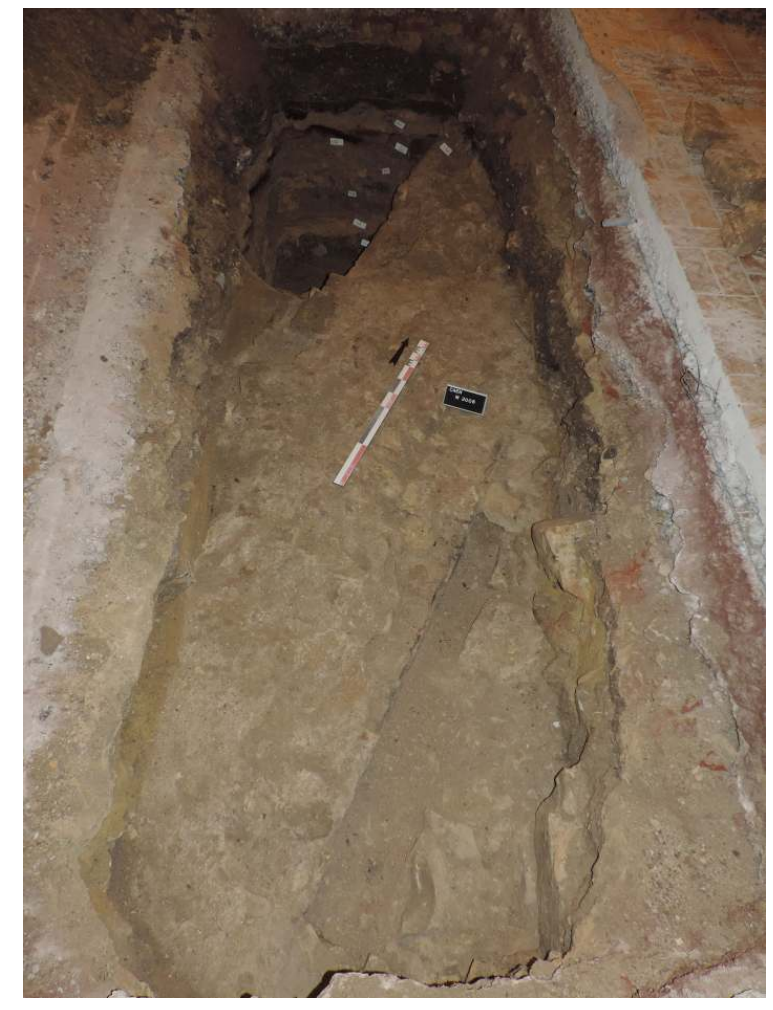

\section{Fig 01}

Vue du sud de l'entrepôt moderne

Cliché : S. Clément-Sauleau, Inrap

INDEX

Index géographique : Basse-Normandie, Calvados (14), Caen

Mots-clés : aménagement hydraulique, bâtiment, entrepôt, occupation technique, occupation administrative

operation Diagnostic (EV)

\section{AUTEURS}

\section{HÉLÈNE DUPONT}

Inrap 